\title{
EJA ENSINO FUNDAMENTAL: A (RE) INCLUSÃO NA ESCOLA COMO PERSPECTIVA DE INSERÇÃO SOCIAL NO TRABALHO
}

\author{
ADULT AND YOUNG EDUCATION AT ELEMENTARY SCHOOL: THE (RE) \\ INCLUSION AT SCHOOL AS PERSPECTIVE OF SOCIAL INSERTION ON LABOUR
}

\author{
J. S. SANTOS ${ }^{1, *}$, I. L. S. CORRÊA ${ }^{2}$ \\ ${ }^{1}$ Pontifícia Universidade Católica do Rio Grande do Sul, Programa de Pós-graduação em Educação, \\ Brasil \\ 2 Universidade Federal do Rio Grande do Sul, Colégio de Aplicação, Brasil
}

\author{
ARTICLEINFO \\ Article history: \\ Received 2018-07-02 \\ Accepted 2018-08-17 \\ Available online 2018-08-31 \\ ${ }^{*}$ Autor correspondente: \\ E-mail: jusantosbr@hotmail.com
}

\begin{abstract}
Palavras-chave: Educação de Jovens e Adultos. Inclusão social. Escola. Trabalho.
\end{abstract}

Keywords: Adult and Young Education. Social Inclusion. School. Work.

RESUMO. Este trabalho tem por objetivo refletir sobre os motivos que levam os estudantes a retornar para a escola na modalidade de Educação de Jovens e Adultos (EJA) enquanto possibilidade de cursar a EJA como um espaço de (re)inclusão na escola excludente. Para realizarmos o estudo aplicamos um questionário com os estudantes da Educação de Jovens e Adultos de uma Escola Municipal de Ensino Fundamental do Município de Porto Alegre - RS e fizemos a análise mediada e referenciada à luz das reflexões freiriana. Como resultados da pesquisa identificaram-se: o processo de juvenilização predominando jovens na faixa-etária de 15 a 18 anos excluídos do Ensino Fundamental regular; a maioria dos jovens busca a EJA com a intenção de concluir o Ensino Fundamental e apropriar-se dos saberes escolar e disciplinar; os mesmos dizem não gostar do descaso de alguns estudantes em algumas disciplinas, e, da aprendizagem e construção do conhecimento em algumas áreas. Percebe-se na fala dos sujeitos da pesquisa que eles desejam uma escola que ensine com seriedade, retidão e Ihes garanta a aprendizagem efetiva. Sendo assim, o nosso estudo destaca a EJA, como um dos poucos espaços de acesso das classes populares aos saberes sistematizados necessários a inclusão social. No entanto, os estudantes ainda reivindicam uma escola que "se ensine e se aprenda com seriedade, mas em que a seriedade jamais vire sisudez" (FREIRE, 2000, p. 24).

ABSTRACT. This essay aims to reflect about the reasons that make the students to come back to school in Adult and Young Education (EJA) as a possibility to attend EJA that is seen as a place of (re)inclusion in the school of exclusion. It was applied a questionnaire with 43 students of a Municipal Elementary school from Porto Alegre / RS in 5th to 9th grades and the analyses were done since Freirian reflections references. As results were identified: a relevant youth process with age average from 15 to 18 years old excluded of regular elementary schools; most of the subjects search for EJA intending to conclude the studies faster and take over 
attitudinal and scholar knowledge; they affirm they do not like the negligence of some students in some school subjects, and the learning and knowledge construction in some areas. It was observed in their speeches that they wish seriousness, rectitude at school that guarantee an effective learning. Thus, our study highlights EJA as one of the fewest places of popular class access to systematized knowledge required to social inclusion. Though students still claim for a school that "teaches and learns with seriousness, but that it never turns into rudeness" (FREIRE, 2000, p.24).

\section{Introdução}

Este texto tem como objetivo refletir sobre os motivos que levam os estudantes a retornar para a escola na modalidade de Educação de Jovens e Adultos (EJA) enquanto possibilidade de cursar a EJA num espaço de (re)inclusão numa escola, por vezes, excludente. Excludente, nesse caso, refere-se ao movimento de algumas escolas de ensino fundamental que retiram seus alunos do turno diurno, pois como os alunos já completaram 15 anos de idade, os mesmos são convidados a frequentar a EJA, no turno noturno.

A nossa preocupação com essa temática dá-se pela experiência dos autores na Educação de Jovens e Adultos e pela constante elevação no número de jovens na EJA de Educação Fundamental. Outra justificativa para essa reflexão é que se observa que muitos estudantes da EJA são oriundos do ensino regular diurno da própria escola que oferece a Educação de Jovens e Adultos. Nesse sentido, a escola que o excluí durante o dia devido a idade, a posturas inadequadas, a necessidade de trabalhar e até mesmo por problemas de envolvimento com drogas ilícitas, os reinsere no turno noturno.

Assim, nos indagamos: esses jovens estão sendo reinseridos na modalidade para obtenção de certificação mais rápida, porque são trabalhadores e necessitam a transferência para o noturno, estão indo para a EJA no intuito de serem inclusos no mercado de trabalho, estão frequentando para administrar o tempo presente? Que motivos são esses para termos tantos jovens frequentando as escolas de ensino fundamental noturno? A escola está tentando incluir quem já fora excluído pela mesma instituição?

Historicamente, sabe-se que no Brasil a EJA foi destinada a possibilitar primeiramente, por vezes a alfabetização aos adultos trabalhadores que não tiveram acesso a Educação Escolar Regular, por necessidade de ingressar precocemente no mercado de trabalho e dessa forma, foram levados a abandonar a escola (PINTO, 2010). Foi na luta pela erradicação do analfabetismo no Brasil que Paulo Freire fez à crítica a educação bancária e propôs uma pedagogia que valorizasse os saberes dos trabalhadores/educandos, o que ainda nos serve 
como inspiração e orientação enquanto educadores dessa modalidade de ensino.

Isto, também nos faz refletir que a educação bancária, a tempo criticada por Freire (1987), é um processo de opressão aos educandos e ainda permanece sendo um dos motivos que levam as classes populares a abandonar a escola. Isto ocorre, pois se continua não valorizando os saberes de jovens e adultos trabalhadores, fato esse, culturalmente enraizado na instituição escola. Essa mesma escola nos moldes bancários que exclui os alunos da escola regular (período matutino e vespertino), tem uma modalidade privilegiada que é a EJA, onde cria ou recria o mesmo espaço escolar, justificando-se com a intenção de incluir esses educandos que já foram excluídos por ela mesma.

Desse espaço da onde falamos, na atualidade muitos dos jovens que são reinseridos na EJA, não necessariamente trabalham durante o dia ou estão matriculados em outros espaços de formação, voltados à inserção social via o mercado de trabalho. Muitos apenas frequentam a escola, pois Ihe foi dado uma segunda chance.

$\mathrm{Na}$ atualidade o que se encontra na EJA do Ensino Fundamental principalmente nos anos finais são jovens que estão frequentando a escola por ser um espaço que ainda os aceita. Um espaço onde eles são reconhecidos pelos professores. Um espaço que, em meio às condições sociais que os mesmos se encontram, ainda faz-se amigável e afetivo nessa modalidade de ensino. (CARRANO, 2007; 2011).

Como procedimentos metodológicos, fizemos uma consulta aos estudantes da Educação de Jovens e Adultos numa Escola Municipal de Ensino Fundamental, do município de Porto Alegre - RS, no sentido de identificarmos os motivos que levam os estudantes a retornar a escola e a importância da EJA para a (re)inclusão escolar. Para isso, aplicamos um questionário com 43 estudantes que frequentavam a EJA nos anos finais do Ensino Fundamental.

A análise dos dados foi realizada a luz do legado freiriano com a inclusão de reflexões a partir das obras de Pinto (2010), Charlot (2000), Lahire (1997), Dayrell (2007) e Carrano (2007; 2011) sendo que esses autores em seus estudos buscam compreender: os motivos que fazem com que os alunos retornem a escola para continuar suas trajetórias educativas; as razões pelas quais eles acreditam que a escola tem como função possibilitar outras perspectivas e planejamentos de futuro exercidos pelos jovens; os conhecimentos e os relacionamentos criados no âmbito escolar; e, os fatores que elevam o sucesso escolar, de acordo com as vivências sociais exercidas pelos sujeitos que frequentam a escola.

\section{Os sujeitos da EJA e os motivos do retorno à escola}

Pinto, ao analisar os sujeitos, que outrora eram na sua maioria mais velhos ao ingressarem na EJA, acredita que esses já possuem seu processo histórico por ora construído 
no momento que retornam a escola, pois fazem parte da sociedade. Alguns já têm suas profissões garantidas, cabendo à escola e a educação apenas "dotá-los de novos conhecimentos, que irão somar ao que já sabe, ou substituir as ideias erradas, ingênuas que possuía." (PINTO, 2010, p.67)

Nesse sentido, o autor traz a importância de percebermos que muitos dos sujeitos que estão frequentando a EJA vêm em busca de conhecimento e não apenas do certificado de conclusão do curso. Os dados obtidos no questionário aplicado demonstram isto parcialmente, porém não podemos ser ingênuos em pensar que todos estão na EJA para obter conhecimento. Muitos das respostas dos alunos mais jovens relatam em suas falas que procuram a EJA, no intuito de acelerar os estudos, devido à quantidade de vezes que não conseguiram concluir seus estudos na idade regular. Para uma parcela desses jovens, estar na escola passa ser um tempo apenas para acabar mais rápido o Ensino Fundamental.

Assim, os estudos de Dayrell (2007) e Carrano (2007; 2011) veem ao longo de duas décadas corroborando para a remodelação da nossa forma de ver os sujeitos frequentadores da EJA, visto que o processo de juvenilização é preeminente na Educação de Jovens e Adultos, e que muitos desses jovens excluídos do ensino regular possuem outras demandas. A demanda por inclusão social nos grupos, por terem sido excluídos devido a tantas causas como: idade avançada, atrasos cognitivos severos, racismo, o bullying vivenciado na atualidade dentro e fora das escolas, entre outros fatos que são narrados e referem-se a suas histórias de vidas truncadas e violentas, que fazem parte da realidade desses sujeitos.

O estudo se fez com 43 estudantes que frequentam a EJA nessa Escola Municipal de Ensino Fundamental do município de Porto Alegre - RS. Desse total, 65\% dos alunos encontram-se na faixa etária dos 15 aos 18 anos, 4\% entre 19 a 29 anos, que são considerados jovens pela OMS , e, $21 \%$ desses sujeitos encontram-se na idade adulta, faixa etária dos 30 a 60 anos sendo que $9 \%$ são idosos que encontram-se com mais de 60 anos, maioria ainda matriculado nos anos iniciais do ensino fundamental.

Os dados para além de demonstrarem um significativo número de jovens frequentadores, também aponta que a maioria dos estudantes frequentadores da EJA, nessa escola investigada, são jovens oriundos do ensino regular da própria escola ou de escolas das comunidades próximas. Esses sujeitos apontam que nunca pararam de estudar, no entanto não chegam ao final do ensino fundamental. 
Apesar dessa constatação voltada ao público juvenil, ressaltamos também que encontramos um número significativo de estudantes, que somente tiveram acesso à escola apenas na modalidade EJA, no entanto, esses, já se encontram na idade adulta ou são idosos.

E para esses adultos, que embora seja em menor número, faz-se necessário como evidenciam Fischer e Franzoi (2009, p. 36) deixar que as experiências desses trabalhadores estudantes e os "saberes trazidos do trabalho invadam o espaço escolar, o que implica considerá-lo par dialético com o professor, sem o qual o processo ensino-aprendizagem não acontece". O diálogo entre saberes escolar e saberes da experiência são desafios cotidianos dos educadores que trabalham com jovens e adultos e que estão presentes nas reflexões dos docentes.

Ao analisarmos a série que o estudante deixou o ensino regular, observamos que: $44 \%$ na $5^{\underline{a}}$ ou $6^{\underline{a}}$ série, $28 \%$ na $7^{\underline{a}}$ ou $8^{\underline{a}}$ série, $10 \%$ na $1^{\underline{a}}$ ou $2^{\underline{a}}$ série, $9 \%$ na $3^{\underline{a}}$ ou $4^{\underline{a}}$ série e 9\% nunca frequentaram a escola antes da EJA. A partir dessa constatação, podemos inferir sobre a razão do fenômeno crescente nos últimos tempos, a juvenilização. Verificou-se que os estudantes ainda adolescentes e jovens estão recorrendo a EJA como uma alternativa ao serem excluídos da escola regular e não necessariamente por já estarem ligados às necessidades oriundas do mercado de trabalho. (FLACH et.al, 2012).

Percebemos que na prática diária, ao conversarmos com os educandos, muitos relatam que foram "convidados" a frequentar a escola da noite, ou que ouviram falas de professores sugerindo um melhor aproveitamento para vida escolar e profissional deles próprios, se frequentassem a EJA, pois seria mais fácil entrar para o mercado do trabalho e continuar estudando.

Curiosamente, muitos desses educandos apresentam um ou mais desses itens juntos: problemas disciplinares, relatos de racismo e bullying, sérias dificuldades de aprendizagem, alguns cumprindo medidas socioeducativas, outros usuários de drogas e a questão da distorção idade e série muito significativa, devido a inúmeras reprovações. Enfim problemas esses, os quais não são fáceis solucionar em meio a um público adulto, imagine então em meio a jovens, considerados menores?

\section{Os motivos do retorno à escola}

Ao questionarmos sobre a razão porque retornaram a escola, tínhamos a hipótese de confirmação dos dados sobre o aceleramento do percurso escolar, porém fomos surpreendidos pelas respostas dos sujeitos investigados nessa escola.

Ao perguntarmos aos estudantes qual a importância da educação escolar, obtivemos: $33 \%$ afirmam buscar uma educação para a vida; 32\% para adquirir conhecimento; $16 \%$ para ter 
um emprego melhor; $14 \%$ ler e escrever; $5 \%$ exigências do trabalho. Sendo assim, se unirmos: conhecimento, ler e escrever como todos sendo pressupostos de conhecimento escolar tem-se que $44 \%$ dos sujeitos vão à escola para ter acesso aos saberes/conhecimentos escolar. E, apenas $21 \%$ estão frequentando a escola devido ao mercado de trabalho, para terem acesso ou manterem-se no emprego.

Esse fator mostra-se relevante, pois demonstra a importância da escola na busca por um ensino que Ihes possibilite o acesso efetivo ao conhecimento, a questões mais amplas que thes possibilitem pensar no mundo do trabalho, como um possível futuro e como diz Arroyo uma possibilidade e "um exercício de emancipação e liberdade". (ARROYO, 2011; PINTO, 2010).

A partir dos apontamentos acima citados, nos questionamos: será que a EJA está atendendo as expectativas dos jovens e adultos? De acordo com Freire (1997) o ensinar exige que o professor crie condições para que os educandos possam refletir sobre os conhecimentos culturais e que possam construir conhecimentos e fazendo uso da curiosidade possam desvelar o mundo e emancipar-se.

E a escola nos moldes atuais cria condições para as classes menos favorecidas? Possui um currículo efetivo que responda as demandas do presente e não apenas do futuro? Demandas de como conseguir a inserção no mercado de trabalho de imediato, aprender coisas significativas em termos de direitos e deveres de cidadãos brasileiros? As escolas de EJA permitem o sucesso escolar e apontam para a transição de nível escolar, intuindo a continuidade? (Arroyo, 2017).

Como constantemente apontado, a escola é um fator importante para todas as classes sociais, nesse sentido, as pesquisas de Lahire (1997) e Charlot $(1996,2000)$ demonstram que as famílias de classes populares dão grande importância à educação escolar, no entanto, isso não garante que os estudantes de classes populares tenham sucesso escolar ou que não abandonam a escola. Segundo esses autores o sucesso escolar depende de relações diversas, familiares, amigos, vizinhos, colegas, professor e a escola. Então, indaga-se, porque os jovens procuram a EJA e não querem mais permanecer no ensino regular?

Sabe-se que a educação bancária além de adestrar corpos, estabelecer linguagem padrão da classe dominante exerce certa violência simbólica (Bourdieu, 2012) o que leva muitos estudantes a abandonar a escola. Nesse sentido, ao perguntarmos aos estudantes porque eles procuraram a EJA tivemos as seguintes respostas: 40\% para terminar os estudos (Ensino Fundamental); $28 \%$ por ser à noite o que viabiliza conciliar com o trabalho diurno; $16 \%$ para aprender mais e $16 \%$ outras respostas as mais variadas possíveis.

Haja vista que a escola seja uma alternativa para a produção e sistematização de conhecimento e reconhecida pelos sujeitos da pesquisa, a EJA transforma-se em uma modalidade de ensino visibilizada como apenas sendo a possibilidades de acelerar o processo de conclusão do Ensino Fundamental. E, embora muitos não trabalhem, reafirmam o discurso elaborado por 
muitos professores que é o da possibilidade de estudar a noite como forma de conciliar estudo e trabalho. (NOSELLA, 1998).

No entanto, questiona-se na atualidade: há emprego bem remunerado para jovens ou adultos trabalhadores sem o ensino fundamental completo? O mercado de trabalho não formal é caracterizado como efetivo para a inserção social? Trabalhar em subempregos e estudar a noite tem a mesma efetividade para adolescentes e jovens alcançar postos de trabalho mais reconhecidos socialmente?

Desse modo, a modalidade EJA voltada ao ensino propedêutico, vem tornando-se cada vez mais um espaço para a aceleração ou inclusão dos excluídos da escola regular do que para conciliar e instrumentalizar sujeitos para o trabalho, visto que a maioria dos jovens permanece desempregado, e durante o dia, ficam pelas ruas ou em frente a tecnologias da informação nas redes virtuais de relacionamento.

Ora também, nos foi apresentado algumas respostas que vão além do "para acabar mais rápido esse negócio", obtivemos respostas tais como: "venho para conviver com pessoas diferentes", "porque estava cansada de acordar cedo, por causa disso faltava muita aula", "tinha muitas crianças pequenas", "ganhamos uma bolsa para estudar", "queria fazer minha carteira de motorista".

Embora, obtivemos como respostas para os motivos de retorno à escola, a predominância da necessidade em ter mais conhecimento, sobretudo porque a sociedade, o trabalho e as próprias relações afetivas impõem isso. Observou-se também, que impera a ligação entre o estudo e a possibilidade de ascensão social e obtenção de um melhor emprego. Ainda predomina no imaginário social a visão da escola, como espaço de redenção e possibilidade de obter o que se espera na vida, através dos estudos, pela obtenção de conhecimentos.

Observa-se que a necessidade de conhecer ou saber é intrínseco ao ser humano e suas relações com o mundo e os outros homens (FREIRE, 1987; CHARLOT, 2000; PINTO, 2010). Para Charlot (2000 p. 78), "a relação com o saber é relação de um sujeito com o mundo, com ele mesmo e com os outros. É relação com o mundo como conjunto de significados, mas também, como espaço de atividades, e se inscreve no tempo". Assim, ao retornar à escola, os estudantes buscam a transformação de sua realidade e veem o conhecimento erudito ou escolar como um passaporte social, que facilitará a (re)inserção social almejada pelas classes populares.

Nesse aspecto, a EJA é vista pelos sujeitos da pesquisa como espaço de tensão e ampliação de "conhecimentos que Ihes permitam elevar-se em sua condição de trabalhador" (PINTO, 2010, p.35), o que se expressa nas falas: "para arrumar um bom emprego e até para saber se comportar numa entrevista de emprego", "para eu me qualificar e ter um serviço melhor", "me ajuda no preparo de ter algum dia uma vida e um emprego melhor". Nessas falas, o conhecimento aparece como uma possibilidade de inclusão social, de ser aceito socialmente; 
Sabe-se também que essa inclusão passa por questões comportamentais, o que fica evidente nessa fala: "saber se portar melhor na sociedade". Aqui, o saber escolar aparece como um aspecto distintivo no sentido de que, ao possuir um saber escolar, um capital escolar e cultural, esse sujeito estará mais bem preparado para ser incluído no espaço social, que permanece distinguindo as pessoas pelo nível de escolaridade que possuem. E, isto também corrobora para dar uma maior autonomia para tentar uma vaga de emprego formal ou, até mesmo, poder fazer uma escolha mais adequada de emprego. (FREIRE, 1996; BOURDIEU, 2011)

Ao tratarmos da motivação para a obtenção de um emprego melhor, como bem retrata Lahire (1997, p. 256), há "exigências cada vez mais elevadas em matéria de cursos de qualificação, o diploma se torna uma necessidade (mesmo que insuficiente) de entrada no mercado de trabalho para o conjunto dos grupos sociais". Para tanto, estudar e adquirir um diploma faz com que alguns alunos veem a escola como um caminho para a ascensão, na busca de um emprego estável e de uma vida social mais justa. Nessa perspectiva, o diploma passa representar um passaporte para disputar uma vaga de emprego tanto na iniciativa privada como nos serviços públicos. (CHARLOT, 1996; BOURDIEU, 2011; LAHIRE, 1997).

Dessa forma, permanece a idealização da escola por parte dos estudantes e da sociedade que pensam que, ao adentrarem os muros da escola, suas vidas serão resolvidas, suas possibilidades de emprego elevar-se-ão e, certamente, suas vidas melhorarão.

Dando seguimento nas análises, ao perguntar o que os estudantes gostam da escola obtivemos: $30 \%$ gostam de aprender ou construir conhecimento; $28 \%$ de algumas disciplinas o que está diretamente relacionado à área de conhecimento; $26 \%$ dos professores e colegas; $9 \%$ dos amigos; 7\% outras respostas.

O destaque para a resposta é que a EJA, mesmo em muitos casos em condições precárias de estrutura, transporte, variação climática com o inverno rigoroso da região sul, a EJA constitui-se num espaço privilegiado que as classes populares devem de terem acesso aos conhecimentos disciplinares e sistematizados sendo-lhes de direito. (PINTO, 2010; FREIRE, 1987, CARRANO, 2007; 2011).

A esperança dos estudantes em aprender os saberes escolares ratifica o papel da escola na atualidade e sendo assim, a escola não deve ser a causa da exclusão de uma parcela de crianças e jovens do acesso a esses saberes. Por isso, busca-se construir "uma escola pública capaz, que se vá construindo aos poucos num espaço de criatividade" (FREIRE, 2000, p.24).

Uma escola democrática em que se pratique a pedagogia da pergunta, da escuta e do diálogo, espaço em que se ensine e se aprenda com seriedade, mas em que a seriedade jamais vire sisudez.

Assim, é sugestivo ficarmos atentos ao que os educandos se referem ao sentir prazer de estar na escola, ao gostar das aulas e das "matérias" ensinadas nas diversas áreas de 
conhecimento, aos momentos lúdicos e de festividades, aos momentos de escuta e diálogo, isto, é fator relevante e pode servir de pistas contra a exclusão escolar, bem como apontar perspectivas para novas abordagens pedagógicas.

Algumas falas trazem isto em evidência: "gosto de conversar com meus professores", "conviver com pessoas da mesma faixa etária que eu e com pessoas mais velhas", "o recreio a noite tem menos gente, me sinto mais tranquilo", "gosto das matérias que me ajudam no dia a dia", "as festas e jantas feitas na escola", "o que mais gosto é a biblioteca", "gosto de trabalhar em grupo" e por fim, "gosto de estudar e da convivência".

Assim, conforme Pinto (2010, p. 47), sendo o conteúdo da educação popular por excelência e direito de todos, "o conteúdo da educação não é um adorno de espírito, mas um 'instrumento de realização do homem' dentro de seu ambiente social”, isto, talvez, justifique o mero desejo de retornar à escola, para ser mais, aprender mais e ampliar sua autonomia.

Ao perguntarmos o que menos gostam da escola obtivemos: $40 \%$ de algumas disciplinas; $30 \%$ do descaso com a aprendizagem por parte de alguns estudantes; $30 \%$ outras respostas. Com esses dados observamos que o desejo por uma escola séria que objetive a aprendizagem é o que a maioria dos estudantes da EJA busca na realidade pesquisada.

Entretanto, o que chama atenção nessa pergunta é que o processo de juvenilização que vem ocorrendo na EJA, onde a natureza pedagógica frente à atualidade ainda permanece nos moldes da educação bancária, não está mais dando conta no enfrentamento com alunos de várias faixas etárias juntas no mesmo espaço de sala de aula. (DAYRELL, 2007; CARRANO, 2007; 2011)

As respostas dos educandos entrevistados nos leva a repensarmos a utilização da mesma prática pedagógica aos jovens e adultos, pois os mesmos estão externalizando o incomodo em relação ao descaso, falta de postura e maturidade de alguns grupos que frequentam a escola, os quais não vêm com o intuito de estudar.

Temos falas como: "não gosto que tem alguns alunos que não tem maturidade para estar a noite e acabam atrapalhando a aula", "acho inconveniente o comportamento dos adolescentes com os professores", "meus colegas são muito novos e atrapalham quem quer aprender", "colega infantis, brincadeiras fora de hora e bagunça", " a bagunça quando o professor está explicando a matéria que tem que aprender" e "as vezes os mais novos ficam dando risada dos outros".

Os aspectos trazidos pelos estudantes como sendo o que menos gostam na escola sinalizam para as relações com os colegas e professores, muitos expressam o desrespeito que alguns têm pelos professores e a importância do espaço escolar na formação das boas relações. Para Charlot (1996, p. 54), existe uma relação direta de "gostar do professor, gostar da matéria", dos "colegas e o ambiente escolar" com o aprender e ter sucesso na escola.

Sendo assim, o que os educandos vêm apontando constantemente como seus desgostos e tristezas nos dizem muito sobre a maneira como estamos a tratar das questões relacionais interpessoais dos jovens com os adultos. Ambos os grupos têm direito ao espaço escolar, porém 
conviver em harmonia torna o momento de aprendizagem mais eficaz e o sucesso escolar fica mais perto de ser atingível, visto que para realmente incluí-los de maneira efetiva como apontam os estudos de autores relevantes no campo da EJA devemos escutá-los e respeitá-los nas suas diversidades.

\section{Considerações finais}

Observa-se, nas respostas desses estudantes, que, quando eles vão à escola, querem que as aulas lhes proporcionem momentos de aprendizagem e é por esse motivo que a maioria dos estudantes se mobiliza. Charlot (1996, p. 55) afirma que a "mobilização em relação à escola é investimento no próprio fato de ir à escola e aprender coisas". Mesmo que a EJA se apresente como um espaço de (re)inclusão, muitas das práticas pedagógicas permanecem pautando-se na educação bancária. Os conhecimentos da cultura dominante ainda são trabalhados, mesmo que de modo fragmentado e verticalizado dentro das disciplinas que compõem o currículo escolar propedêutico na EJA. Porém, esses mesmos conteúdos, fazem com que em muitos casos, seja mais uma vez a causa da exclusão dos estudantes ao acesso aos saberes escolar. Isto ocorre, pois, esses saberes desvinculados dos saberes dos sujeitos e acima de tudo das necessidades que esses sujeitos têm, os desestimula corrobora a exclusão escolar.

Contudo, as falas dos estudantes da EJA nos dizem muito e nos levam a concluir que esses sujeitos desejam uma escola que lhes garanta o acesso ao conhecimento sistematizado e que o diploma escolar, ou seja, o capital escolar e cultural venha a garantir sua inclusão social. Esses alunos também reivindicam maior seriedade na prática pedagógica da EJA, pois necessitam de conhecimentos voltados a suprir suas necessidades, para então, planejar e ter perspectiva de futuro.

Nesse sentido, para que a EJA se consolide de fato como um espaço de (re)inclusão na escola excludente, esse estudo aponta para pensarmos e efetivarmos através das nossas práticas pedagógicas a luta por uma educação de EJA com maior seriedade, amorosidade, respeito aos saberes dos educandos, num espaço que consiga ser crítico, dialógico e alegre. Porém, há outras indagações: como efetivarmos através de um currículo normativo, fragmentado e verticalizado a inserção desse jovem desempregado ao mercado de trabalho? Como introduzir novos conhecimentos que eleve a condição e a autonomia dos adultos que retornam para a EJA com a perspectiva de ascender profissionalmente e quiçá mudar de trabalho? Como efetivar a transição desse jovem e desse adulto a uma escola de ensino médio ou a um curso técnico com o distanciamento político que há entre as escolas regulares de ensino propedêutico e os institutos federais profissionalizantes? 
Enquanto não tivermos respostas para essas questões, a EJA que atende o ensino fundamental ainda permanece distante da realidade da EJA de Ensino Médio, PROEJA, ensino profissionalizante, pois ainda não se percebeu que vivenciamos duas demandas completamente diversas, porém ambas significativas. A dicotomia conflitante na EJA sempre ocorre ao pontuarmos os sujeitos dessa modalidade. Se por um lado, temos esse jovem matriculado, o qual não está pensando no seu futuro. Esse sujeito jovem, que já fora excluído e que demanda reposta ao seu presente e as suas necessidades do agora. Por outro lado, temos que repensar um currículo e uma organização de tempo e espaço para esse sujeito adulto, também frequentador com outras demandas. Sujeitos adultos, que possuem necessidades diferentes e os quais, certamente, não possuem o mesmo tempo de expectativa que os jovens, mas que também estão na escola em busca de conhecimentos que, ao serem inseridos no mercado de trabalho, também Ihes fizeram falta.

Por isso, pensar nos sujeitos da EJA é certamente pensar uma escola que poderia auxiliá-lo com um ensino voltado as demandas mais adultas e com perspectivas de avanços pessoais e profissionais através dos saberes escolar. Repensar o currículo e sua abordagem voltados a esse sujeito é imprescindível. Um currículo, que ao menos possa encaminhá-lo para uma transição que seja no âmbito escolar ou para o mercado de trabalho formal, mas que efetivamente possa reinseri-lo socialmente. (OLIVEIRA, 2007: 2009).

Para finalizar, pode-se dizer que não há conclusões quando a temática e o sujeito da EJA, o que há é uma demanda urgente de estudarmos mais essa nova realidade plural que nos é apresentada e, tentarmos efetivar mudanças urgentes no currículo e nas escolas que atendem a EJA na atualidade.

\section{Referências}

ARROYO, Miguel G.. Educação de Jovens e Adultos: um campo de direitos e de responsabilidade pública. In. Miguel Arroyo: educador em diálogo com nosso tempo. Belo Horizonte, MG: Autêntica, 2011.

ARROYO, Miguel G.. Passageiros da noite: do trabalho para a EJA: itinerários pelo direito a uma vida justa. Petrópolis, RJ: Vozes, 2017.

BOURDIEU, Pierre. A Distinção: crítica social do julgamento. Trad. De Daniela Kern; Guilherme. F. Teixeira. Porto Alegre, RS: Zouk, 2011.

BOURDIEU, Pierre. A reprodução: elementos para uma teoria do sistema de ensino. Trad. De Reynaldo Bairão. Petrópolis, RJ: Vozes, 2012.

CARRANO, Paulo. Educação de Jovens e Adultos e Juventude: o desafio de compreender os sentidos da presença dos jovens na escola da "segunda chance". In: Revista REVEJA (UFMG), online, 2007. 
CARRANO, Paulo. A escola diante das culturas juvenis: reconhecer para dialogar. Revista Educação, Santa Maria, v. 36, p. 43-56, jan./abr. 2011.

CHARLOT, Bernard. Da relação com o saber: elementos para uma teoria. Porto Alegre: Artes Médicas, 2000.

CHARLOT, Bernard. Relação com o saber e com a escola entre estudantes de periferia. Cadernos de Pesquisa. São Paulo. n. 97, maio, 1996. p. 47-63

DAYRELL, Juarez. A escola "faz" as juventudes? Reflexões em torno da socialização juvenil. Educ. Soc., Campinas, vol. 28, n. 100 - Especial, 2007.

FLACH, Pâmela Z.S. et. al. Retratos das múltiplas juventudes presentes na educação de jovens e adultos. In. GODINHO, Ana Claudia F. et al. (Orgs.). Entre imagens e palavras: práticas e pesquisas na EJA. Porto Alegre, RS: Panorama Crítico, 2012.

FISCHER, Maria Clara Bueno; FRANZOI, Naira Lisboa. Formação humana e educação profissional: diálogos possíveis. Educação, Sociedade \& Culturas, ํㅡ29, 2009.

FREIRE, Paulo. A educação na cidade. São Paulo: Cortez, 2000.

FREIRE, Paulo. Pedagogia da autonomia: saberes necessários a prática educativa. São Paulo: Paz e Terra, 1997.

FREIRE, Paulo. Pedagogia do Oprimido. 17 ed. Rio de Janeiro: Paz e Terra, 1987.

LAHIRE, Bernard. Sucesso escolar nos meios populares: as razões do improvável. São Paulo: 1997.

NOSELLA, Paulo. A escola brasileira no final de século: um balanço. In. FRIGOTTO, Gaudêncio (org.). Educação e crise no trabalho. Petrópolis: Vozes, 1998.

OLIVEIRA, Inês Barbosa de. Reflexões acerca da organização curricular e das práticas pedagógicas na EJA. Educ. rev. [online]. 2007, n.29, pp.83-100.

OLIVEIRA, Inês Barbosa de. Organização curricular e práticas pedagógicas na EJA: algumas reflexões. In: PAIVA, Jane; OLIVEIRA, Inês Barbosa de. (Orgs.) Educação de jovens e Adultos. Petrópolis: DP et Alii, 2009.

PINTO, Álvaro Vieira. Sete lições sobre educação de adultos. 16 ed. São Paulo: Cortez, 2010. 